\title{
Epstein-Barr Virus latent membrane protein I induces Snail and epithelial-mesenchymal transition in metastatic nasopharyngeal carcinoma
}

\author{
T Horikawa ${ }^{1,2}$, T Yoshizaki ${ }^{2}$, S Kondo², M Furukawa², Y Kaizaki ${ }^{3}$ and JS Pagano*,I \\ 'Lineberger Comprehensive Cancer Center, University of North Carolina at Chapel Hill, CB\# 7295, Chapel Hill, NC 27599-7295, USA; ${ }^{2}$ Department of \\ Otolanyngology, School of Medicine, Kanazawa University, I 3-I Takara-machi, Kanazawa 920-864 I, Japan; ${ }^{3}$ Department of Pathology, Fukui Prefectural \\ Hospital, 2-8-I Yotsui, Fukui 9l 0-8526, Japan
}

BACKGROUND: Epstein-Barr Virus (EBV)-associated nasopharyngeal carcinoma (NPC) is distinctive among head-and-neck cancers in its undifferentiated histopathology and highly metastatic character. We have recently investigated the involvement of epithelialmesenchymal transition (EMT) in NPC. In a previous study, we found a close association of expression of LMPI, the principal EBV oncoprotein, with expression of Twist and induction of EMT.

METHODS: We analysed expression of Snail in 4I NPC tissues by immunohistochemistry. The role of Twist as well as Snail in EMT of NPC was investigated by using NP69SV40T human nasopharyngeal cells.

RESULTS: In NPC tissues, overexpression of Snail is associated with expression of LMPI in carcinomatous cells. In addition, expression of Snail positively correlated with metastasis and independently correlated inversely with expression of E-cadherin. Expression of Twist had no association with expression of E-cadherin. Further, in a human nasopharyngeal cell line, LMPI induces EMT and its associated cellular motility and invasiveness. Expression of Snail is induced by LMPI in these cells, and small hairpin RNA (shRNA) to Snail reversed the cellular changes. By contrast, Twist did not produce EMT in these nasopharyngeal cells.

CONCLUSIONS: This study strengthens the association of EMT with the metastatic behaviour of NPC. These results suggest that induction of Snail by the EBV oncoprotein LMPI has a pivotal role in EMT in NPC.

British Journal of Cancer (201 I) I 04, II60-1|67. doi:10.1038/bjc.201।.38 www.bjcancer.com

Published online 8 March 2011

(C) 2011 Cancer Research UK

Keywords: Snail; latent membrane protein I; epithelial-mesenchymal transition; metastasis; nasopharyngeal carcinoma

Evidence has been growing that metastatic carcinoma cells activate the dormant epithelial-mesenchymal transition (EMT) programme, which promotes cell migration, invasion and metastasis (Yang and Weinberg, 2008; Thiery et al, 2009). Epithelialmesenchymal transition is a process whereby epithelial cells lose cell-cell contacts and undergo remodelling of the cytoskeleton, thus resulting in a migratory phenotype. Epithelial-mesenchymal transition was first recognised in embryogenesis, and recently it has been implicated in several metastatic malignancies including nasopharyngeal carcinoma (NPC) (Yang et al, 2004; Rees et al, 2006; Horikawa et al, 2007; Yang and Weinberg, 2008; Thiery et al, 2009). Moreover, recent studies of EMT have fuelled a change in paradigm on occurrence of cancer metastases from the late metastasis theory to the early metastasis model (Ansieau et al, 2008; Klein, 2008; Mani et al, 2008; Sánchez-García, 2009).

Nasopharyngeal carcinoma, a cancer with high incidence in southeast Asia, is known for its highly metastatic character in early stages of the disease (Lo et al, 2004; Wei and Sham, 2005; Lo et al, 2006). Also, no human carcinoma is as consistently associated with

*Correspondence: Dr JS Pagano; E-mail: joseph_pagano@med.unc.edu Received 27 October 2010; revised 19 January 2011; accepted 24 January 201 I; published online 8 March 2011
Epstein-Barr Virus (EBV) as NPC, and EBV, the first human tumour virus, is intimately associated with its oncogenesis (RaabTraub, 2002; Lo et al, 2004; Pagano et al, 2004; Wei and Sham, 2005; Lo et al, 2006; Pagano, 2010). The present study derives from the hypothesis that the distinctive undifferentiated histopathology and early metastatic character of NPC might point to the occurrence of EMT induced by EBV in the genesis of this tumour. Tumour cells of undifferentiated NPC exhibit EMT-like phenotypes: irregular morphology with loss of tight intracellular adhesion and epithelial structures; diffusely infiltrative growth histologically; and metastasis-proneness from early phases of the disease (Marks et al, 1998; Wei and Sham, 2005).

Latent membrane protein 1 (LMP1) is the principal EBV oncoprotein and required for immortalisation of B-lymphocytes (Kaye et al, 1995). LMP1 acts as a constitutively active EGF receptor-like, but ligand-less molecule and is considered to contribute to initiation of EBV-related malignancies (Knecht et al, 2001). It is detected in at least $70 \%$ of NPC at the protein level and in virtually all at the RNA level (Pathmanathan et al, 1995). Besides its aetiologic role, LMP1 has been implicated in tumour progression (Yoshizaki et al, 1998, 2005; Lo et al, 2006). The propensity to metastasis of EBV-related malignancies corresponds with the expression of LMP1 (Pagano, 2009). Nasopharyngeal carcinomas with high levels of LMP1 tend to be 
more metastatic than those with low levels (Horikawa et al, 2000, 2001; Sarac et al, 2001). Further, underpinning these associations are numerous observations that LMP1 can upregulate a constellation of metastasis-related factors (Takeshita et al, 1999; Murono et al, 2000, 2001; Yoshizaki et al, 2001; Wakisaka et al, 2002, 2004; Wakisaka and Pagano, 2003; Kondo et al, 2005, 2006a, b, 2007; Endo et al, 2009).

Twist, Snail, SIP1 and Slug are known as prominent E-cadherin repressors and EMT regulators (Yang and Weinberg, 2008). Different levels of expression and roles for these regulators have been reported in a variety of invasive carcinomas. Snail, a zincfinger transcription factor, is a representative regulator of EMT during embryogenesis (Barberà et al, 2004; Bachelder et al, 2005). More importantly, the expression of Snail is upregulated in invasive types of carcinoma cell lines (Cano et al, 2000) and in invasive human carcinomas, including undifferentiated breast carcinomas (Blanco et al, 2002) and hepatocellular carcinomas (Yang et al, 2009). Snail increases aggressiveness of experimentally induced breast tumours, and its overexpression is associated with recurrence of human breast cancer (Moody et al, 2005). However, the pathogenesis of EMT and upstream signalling pathways for EMT regulators in malignancies are still not well understood.

In a recent study, we reported the association of EMT with metastatic NPC. We found that LMP1 induces EMT through Twist in the Madin-Darby Canine-Kidney (MDCK) cell line and that Twist is associated with LMP1 and metastasis in NPC (Horikawa et al, 2007). Here, we explore further the involvement of EBV and EMT in metastasis and NPC in relation to the EMT regulators, Snail, SIP1 and Slug. Instead of canine-kidney cells, we exploit a newly established human nasopharyngeal cell line for this purpose. Interestingly although the expression of Snail is also associated with LMP1 and with metastasis, the level of Snail, but not Twist, inversely correlated with the level of E-cadherin in NPC. Snail appears to be essential for induction of EMT by LMP1 as shown when its expression is inhibited by Snail shRNA in the human nasopharyngeal cells. Twist did not produce EMT in these nasopharyngeal cells. These results suggest that Snail has a pivotal role in EMT and metastasis in NPC.

\section{MATERIALS AND METHODS}

\section{NPC tissues}

A total of 41 tissues from paraffin-embedded NPC specimens were from Fukui Prefectural Hospital, Fukui, Japan. Tissues from 37 cases from the same set used in our previous study (Horikawa et al, 2007) plus four additional cases were analysed.

\section{Immunohistochemical analysis}

Immunohistochemistry was done as described before (Horikawa et al, 2000, 2001, 2007). Primary antibodies used were: mouse LMP1 monoclonal antibody from DAKO (Grostrup, Denmark), goat Snail, rabbit SIP1, rabbit Slug and rabbit Twist polyclonal antibodies, and mouse E-cadherin monoclonal antibody from Santa Cruz Biotechnology (Santa Cruz, CA, USA). Two examiners independently selected two representative fields of more than 200 tumour cells from each tissue specimen and counted both stained and total number of tumour cells without knowledge of the clinical data. Average percentages of stained cells were used to calculate the LMP1, Snail, SIP1, Slug, Twist and E-cadherin expression scores, as in our previous study (Horikawa et al, 2000, 2001, 2007, 2008). Staining was repeated at least twice in sequential sections to assess reproducibility. The expression scores of LMP1 and Twist for 37 cases were taken from our previous results (Horikawa et al, 2007) and analyzed again to derive a score that included the additional four cases. Staining of LMP1 and Twist for the previous 37 cases was done again to confirm reproducibility.

\section{Statistical analysis}

Pearson's correlation coefficient was used to detect correlations among the expression scores of each protein analyzed in NPC. The expression score of each protein in relation to clinical data was analyzed with the Mann-Whitney $U$-test. The differences in wound migration and invasion indices between NP69SV40T cell clones were analyzed by the paired $t$-test.

\section{Cell cultures}

NP69SV40T immortalised human nasopharyngeal epithelial cells were the kind gift of Dr Sai Wah Tsao, University of Hong Kong, Hong Kong, China (Tsao et al, 2002). Cells were maintained as described (Tsao et al, 2002).

\section{Plasmids and small hairpin RNA}

PcDNA3-based LMP1 plasmid has been described (Yoshizaki et al, 1998). The pSUPER-Snail-shRNA and pSUPER-control-shRNA were kind gifts from Dr Gerhard Christofori (University of Basel, Basel, Switzerland) and have been described previously (Grotegut et al, 2006).

\section{Transient and stable transfections}

Cells were transfected with FUGENE6 transfection reagent (Roche Diagnostics, Indianapolis, IN, USA). Stable cell lines expressing LMP1 were established in the presence of $500 \mu \mathrm{g} \mathrm{ml}^{-1} \mathrm{G} 418$.

\section{Retroviral transduction}

Retroviral transduction has been described previously (Moody et al, 2005). Snail-shRNA and control-shRNA infected cells were selected with $2 \mu \mathrm{g} \mathrm{ml}^{-1}$ puromycin.

\section{Western blot analysis}

Cell lysates $(100 \mu \mathrm{g})$ were analyzed for protein levels by western blotting (Wakisaka et al, 2002). Primary antibodies for LMP1, Snail and E-cadherin are the same as those used for immunohistochemistry. Primary antibodies: $\alpha$-catenin polyclonal antibody, goat vimentin polyclonal antibody and rabbit N-cadherin polyclonal antibody from Santa Cruz Biotechnology; and mouse $\gamma$-tubulin monoclonal antibody from Sigma (St Louis, MO, USA).

Reverse-transcriptase polymerase chain reaction (RT-PCR) analysis. RT-PCR for Snail was carried out as described with specific primers as follows: sense, 5-TGCGCGAATCGGCGACCC-3; antisense, 5-CCTAGAGAACCGCTTCCCGCAG-3 (product size, $600 \mathrm{bp}$ ) (Elloul et al, 2005).

\section{Invasion assay and cell wound-migration assay}

Cell invasiveness was assessed in Biocoat Matrigel Invasion Chambers (Becton Dickinson Labware, Bedford, MA, USA) (Murono et al, 2000; Horikawa et al, 2007). Cell wound-migration assay was done as described before (Horikawa et al, 2007).

Immunofluorescence studies. Procedures were performed as described (Gershburg et al, 2004; Horikawa et al, 2007). Primary antibodies for Snail, E-cadherin and N-cadherin were the same as used for immunohistochemistry.

\section{RESULTS}

\section{Snail is overexpressed in NPC tumours}

Overexpression of Twist in NPC was reported recently (Horikawa et al, 2007) and is shown again in Figure 1B. Here, we examine 




B

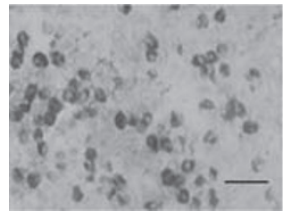

Twist

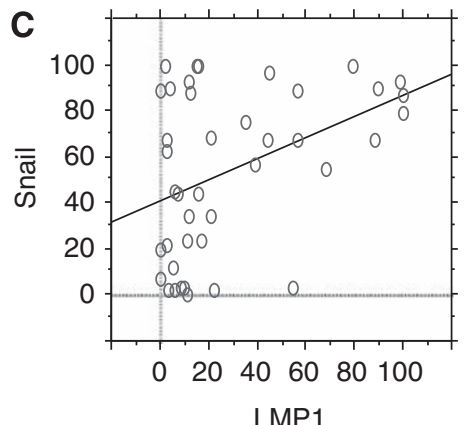

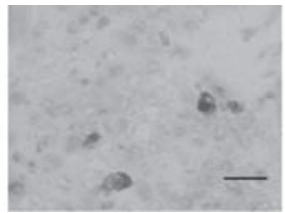

SIP1

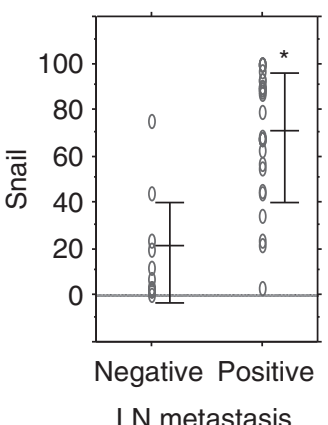



Slug

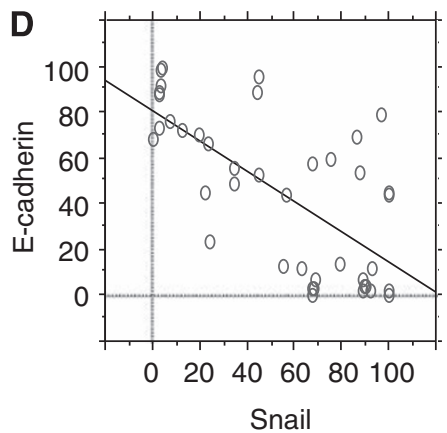

Figure I Expression of Snail and LMPI are associated, and Snail correlates directly with metastasis and inversely with expression of E-cadherin in NPC. (A) LMPI and Snail are overexpressed in NPC tumour cells, but not detected in adjacent normal nasopharyngeal epithelium by immunohistochemistry. Representative results in NPC and in normal nasopharyngeal epithelium are shown. Bars, $50 \mu \mathrm{m}$. (B) Twist, SIPI and Slug are expressed in nuclei of tumour cells in NPC; Twist is highly expressed in tumour-cell nests. (C) Expression scores of Snail and LMPI correlated significantly in NPC: Pearson's correlation coefficient, $r=0.415, P=0.0065$. Expression levels of Snail in relation to incidence of cervical lymph-node metastasis. *Significance according to Mann-Whitney $U$ test, $P<0.000$ I. (D) Expression of Snail correlates inversely with expression of E-cadherin in NPC $(r=-0.68, P<0.000 \mathrm{I})$.

expression of representative EMT regulators Snail, SIP1 and Slug by immunohistochemistry in NPC tissue sections. Staining for SIP1 and Slug was detected in the nuclei of tumour cells, but expression was sporadic and at very low levels (Figure 1B). By contrast, Snail was readily detected in the nuclei of tumour cells and was clearly overexpressed in tumour nests (Figure 1A).

\section{Expression of Snail correlates with expression of LMP1 in NPC and correlates directly with metastasis}

We analyzed if there is correlation of expression of Snail, SIP1 or Slug with LMP1 in NPC. Neither the expression of SIP1 nor Slug showed such an association (data not shown), whereas analysis of
Snail revealed significant positive correlation with expression of LMP1 $(r=0.415, P=0.0065)$ (Figure 1C). Clinically, regional lymph-node invasion is the most common presenting finding in NPC (Lo et al, 2004), mirroring its highly metastatic character. NPC often shows marked cervical lymph-node metastasis before forming a mass in the primary site. In 29 cases with cervical lymph-node metastasis, the Snail expression score was $69.5 \pm 27.1$ (mean \pm s.d.). In 12 cases without metastasis, the score was $16.4 \pm 22.5$. Thus, Snail expression in metastasis-positive cases was significantly higher than in metastasis-negative cases $(P<0.0001)$ (Figure 1C). Expression of Twist also significantly correlated with cervical lymph-node metastasis in the 41 cases studied $(P=0.001)$. 
Expression of Snail correlates independently inversely with expression of E-cadherin

Having found close association of Snail as well as Twist with metastasis of NPC, we next probed for evidence of EMT in NPC tissue. Snail and Twist repress E-cadherin through binding to E-boxes in the E-cadherin promoter and induce EMT (Yang and Weinberg, 2008). Downregulation of E-cadherin is a hallmark of EMT (Thiery et al, 2009). Therefore, we examined expression of E-cadherin and analysed its association with the EMT regulators in NPC. E-cadherin was regularly detected on membranes of tumour cells by immunohistochemistry. Expression of neither SIP1 nor Slug was associated with expression of E-cadherin (data not shown). Unexpectedly, expression of Twist was not associated with expression of E-cadherin $(r=-0.22, P=0.17)$, whereas the pattern of expression of Snail appeared to be the inverse of that of E-cadherin. In normal nasopharyngeal epithelium, cells are tightly packed and structured. Here, expression of E-cadherin is highly conserved, and expression of neither LMP1 nor Snail proteins was detected (Figure 1A). By contrast, in NPC tumour nests where undifferentiated tumour cells show disseminative and diffusely organised morphology, LMP1 as well as Snail protein were overexpressed, whereas the expression of E-cadherin was at low levels (Figure 1A). As shown in Figure 1D, the expression of Snail correlated inversely with the expression of E-cadherin in NPC $(r=-0.68, P<0.0001)$. The results indicate the close association of Snail, but not Twist, with EMT in NPC.

\section{LMP1 could induce Snail in AdAH nasopharyngeal cells}

Having found a close association of Snail with LMP1 in NPC, we explored whether LMP1 can induce Snail in the human nasopharyngeal epithelial cell line, AdAH, used for study of LMP1 in previous studies (Yoshizaki et al, 2005). In AdAH cells transiently transfected with LMP1, Snail was induced in dosedependent manner (Figure 2A). Stable expression of LMP1 also increased the level of Snail protein (Figure 2B) and mRNA (Figure 2C).

\section{LMP1 induces EMT phenotype in NP69SV40T human nasopharyngeal cells}

We previously found that LMP1 could induce EMT in the canine cell line MDCK, and Twist has an important role in this context (Horikawa et al, 2007). Snail was not upregulated by LMP1 and was not involved in LMP1-induced EMT in MDCK cells (data not shown). However, the present analyses of NPC tissues suggested that Snail might be more closely involved with EMT in NPC than
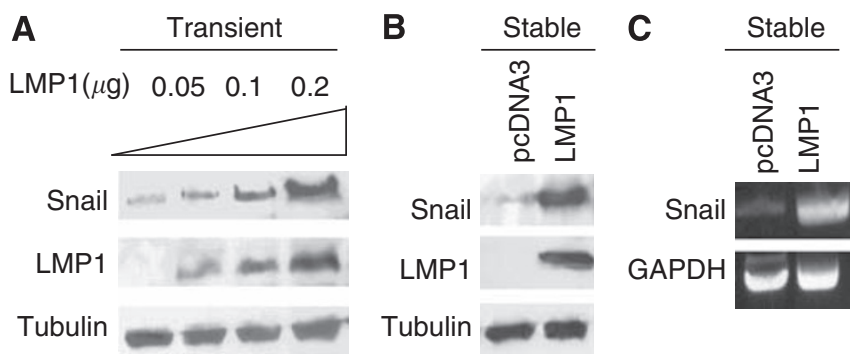

Figure 2 Expression of Snail protein and mRNA is induced by LMPI in Ad-AH human nasopharyngeal epithelial cells. (A) Different amounts of LMPI expression plasmid were transiently transfected and Snail protein levels were determined by western blotting. (B) Expression of Snail is increased in Ad-AH cells stably expressing LMPI. (C) Snail mRNA level is upregulated by LMPI. Extracts from the same cells in Figure $2 \mathrm{~B}$ were analyzed by RT-PCR
Twist. Therefore, we extended our studies of involvement of these EMT regulators by exploiting a new human cell-culture model. Madin-Darby Canine-Kidney cells are widely used as the model cells for study of EMT (Horikawa et al, 2007; Thiery et al, 2009), but they are canine-kidney cells and may not be best suited for study of a human virus. We have been using human AdAH nasopharyngeal cells in a series of studies of LMP1's role in metastasis, but in AdAH cells, LMP1 produced neither morphological change nor EMT-like features (Yoshizaki et al, 2005; Horikawa et al, 2007).

An immortalised human nasopharyngeal epithelial cell line, NP69SV40T, was derived recently from primary non-malignant nasopharyngeal epithelial cells (Tsao et al, 2002). It is highly responsive to LMP1 and offers a new cell system for study of the role of EBV in NPC (Tsao et al, 2002; Lo et al, 2006). First, we tested whether EBV LMP1 could also induce EMT in this more relevant cell system. Parental NP69SV40T and cells stably transfected with a control plasmid exhibited typical polygonal epithelial cell morphology and grew in a cohesive pattern (Figure 3A). By contrast, LMP1 transfectants acquired an elongated fibroblast-like appearance and grew in a scattered pattern with reduction in cell-to-cell contacts (Figure 3A). These changes represent hallmarks of EMT.

\section{Snail, but not Twist, is important for induction of EMT, cell migration and invasiveness by LMP1 in human nasopharyngeal cells}

We examined expression of Twist in NP69SV40T cells. Twist was detected in trace amounts in these cells. In contrast to MDCK cells, levels of Twist were not upregulated by LMP1 (Figure 4A). Neither SIP1 nor Slug was detected in clones of NP69SV40T cells. We next explored involvement of Snail in LMP1-induced EMT in this nasopharyngeal cell line. Expression of Snail was clearly upregulated by LMP1 in NP69SV40T cells (Figure 4B). Moreover, silencing of Snail expression by Snail small hairpin RNA (shRNA) in LMP1-transfected NP69SV40T cells largely reversed the cellular phenotype to an epithelial morphology (Figure 3A). Transduction of Twist siRNA in LMP1-transfected NP69SV40T cells did not change the cellular phenotype (Figure $3 \mathrm{~B}$ ).

In a wound-induced cell-migration assay, LMP1-transfected NP69SV40T cells migrated into the wounded area away from the monolayer edges (Figure 3C). Suppression of expression of Snail expression with shRNA clearly reduced such cellular motility (Figure 3C). Also, in a Matrigel cell-invasion system, LMP1induced invasiveness was significantly inhibited by Snail shRNA (Figure 3D). Thus, Snail, but not Twist, is critical for causing LMP1-induced EMT and invasive properties in these human nasopharyngeal cells.

\section{Molecular markers confirmed the essential role of Snail in LMP1-induced EMT}

In addition, we examined levels of epithelial and mesenchymal markers in NP69SV40T cells. Upon transfection with LMP1, the level of representative epithelial cell markers decreased, whereas the expression of mesenchymal markers increased markedly (Figure 4B). Immunofluorescence studies confirmed the disappearance of E-cadherin from cell membranes as well as the induction of $\mathrm{N}$-cadherin in the cytoplasm caused by LMP1 (Figure 4C). Hence, molecular changes confirmed that LMP1 induces EMT in human nasopharyngeal cells. Further, in the Snail shRNA-transfectants, changes in expression of the molecular markers were consistent with mesenchymal-to-epithelial transition (MET), the reverse of EMT (Yang and Weinberg, 2008; Thiery et al, 2009). This result fortified the conclusion that EBV LMP1 can induce EMT in NPC as well as underscore the principal role of Snail in this process. 
A

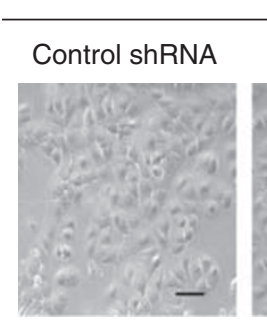

Vector

Snail shRNA

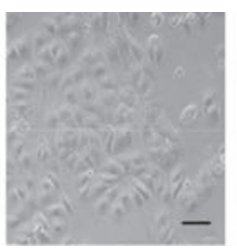

LMP1

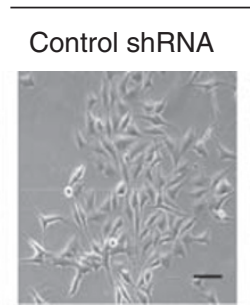

B LMP1



C


Vector

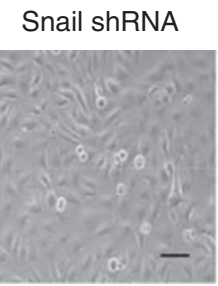

LMP1



D

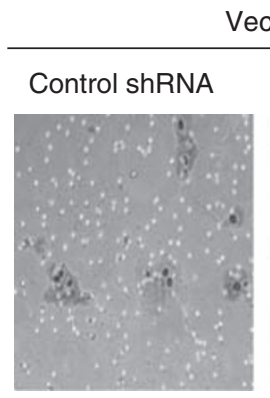

Vector


LMP1
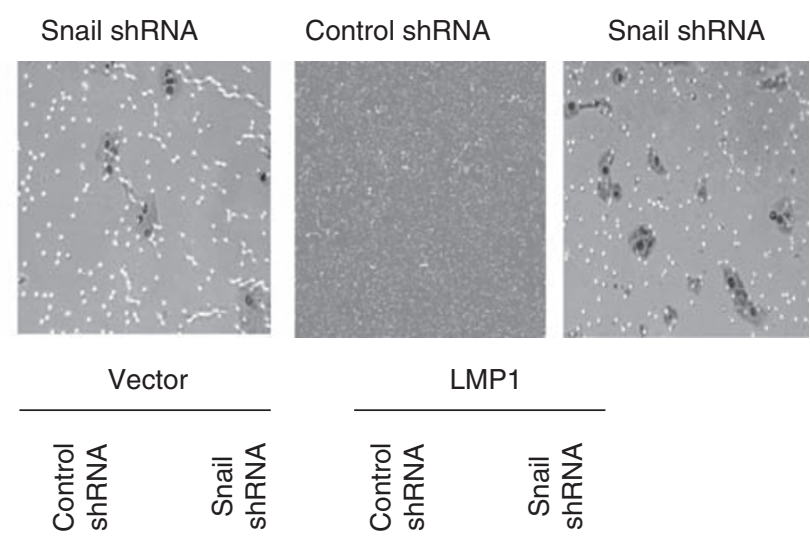

LMP1

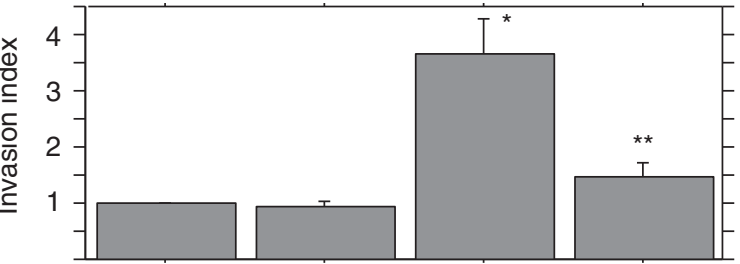

Figure $3 \mathrm{LMPI}$ induces EMT phenotype through Snail in a human nasopharyngeal cell line. (A) Morphological changes in NP69SV40T nasopharyngeal epithelial cells induced by transfection with LMPI could be reversed by Snail shRNA. Snail shRNA and control shRNA were transduced by the retroviral system to generate stable clones. NP69SV40T cell clones, $2 \times 10^{5}$ cells per dish, were plated onto 35 -mm plastic dishes and observed after $24 \mathrm{~h}$ Representative clones are shown. Bars, $50 \mu \mathrm{m}$. (B) Transduction of Twist siRNA in LMPI-transfected NP69SV40T cells did not change the cellular phenotype. (C) Scrape-wound migration assay shows that enhanced motility in LMPI-transfected cells is downregulated by silencing Snail through Snail shRNA. Confluent monolayers of NP69SV40T nasopharyngeal epithelial cell clones were scraped with a plastic pipette tip, and migration of cells was observed. Typical wounds at 0 and IO h are shown. Bars, $200 \mu \mathrm{m}$. (D) Enhanced invasiveness of LMPI-transformed cells is downregulated by Snail shRNA. After $72 \mathrm{~h}$ in the Matrigel invasion assays, each NP69SV40T cell clone adherent on the lower surface of the filter was fixed and stained. Representative photographs are shown. Bar, $50 \mu \mathrm{m}$. Invasion indices were calculated from the counts of cells invading through Matrigel-coated membrane. Significance was tested by paired $t$-test. $* P=0.0007$ as compared with control cells (NP69SV40T + vector + control shRNA cells); $* * P=0.004 I$ as compared with NP69SV40T + LMPI + control shRNA cells. 
A

B

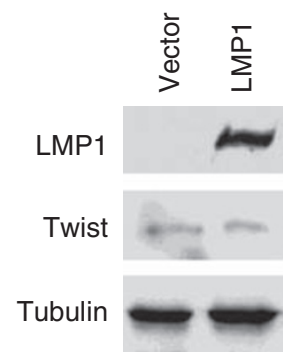

\begin{tabular}{|c|c|c|c|}
\hline \multicolumn{2}{|c|}{ Vector } & \multicolumn{2}{|c|}{ LMP1 } \\
\hline 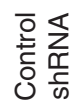 &  &  & 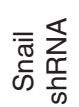 \\
\hline
\end{tabular}

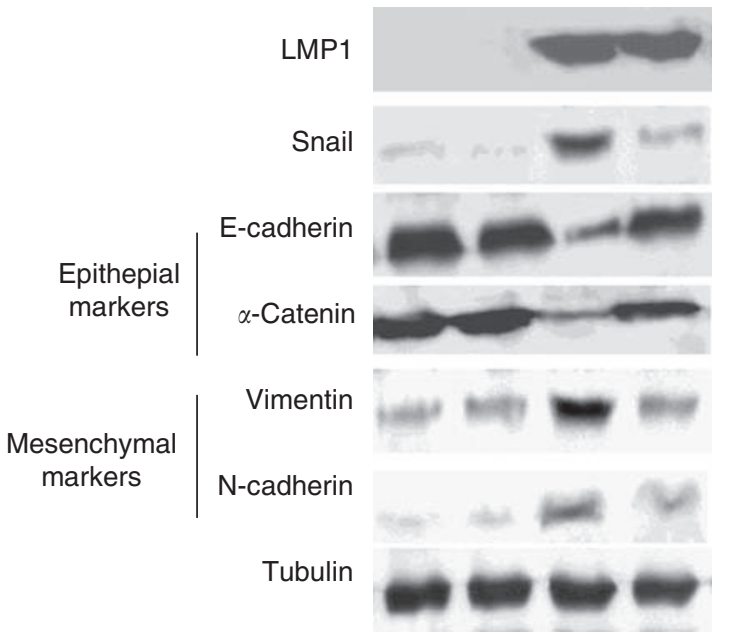

C

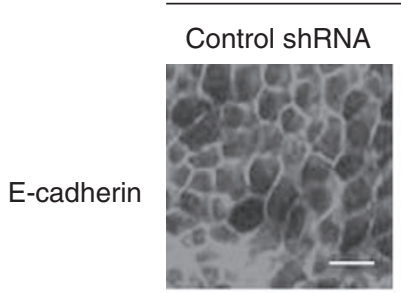

Vector
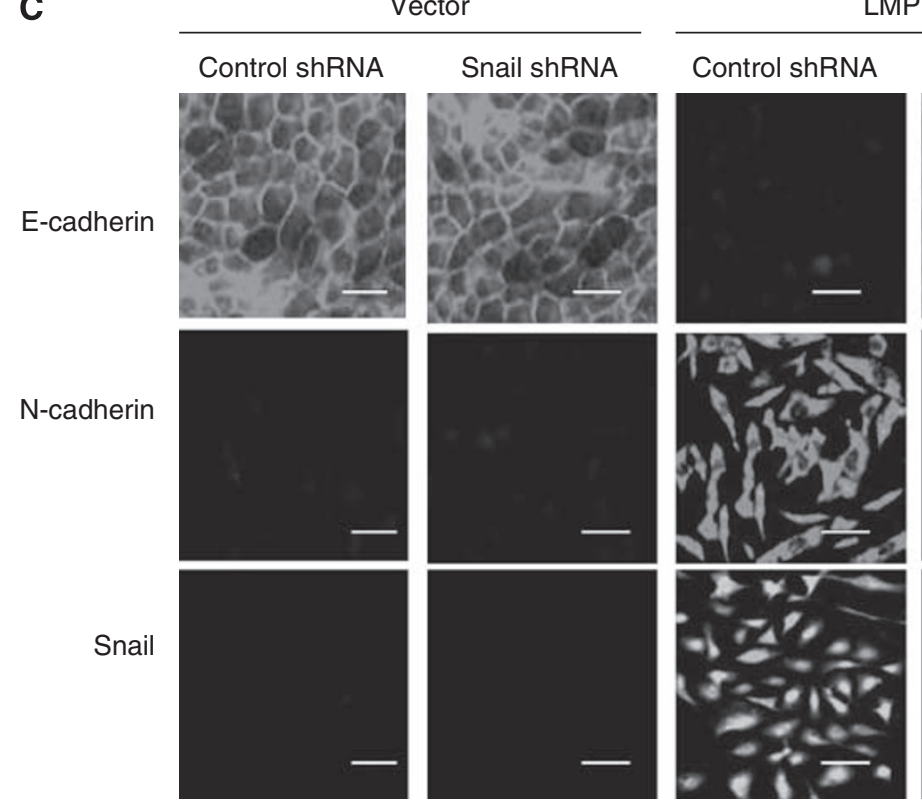

MP1
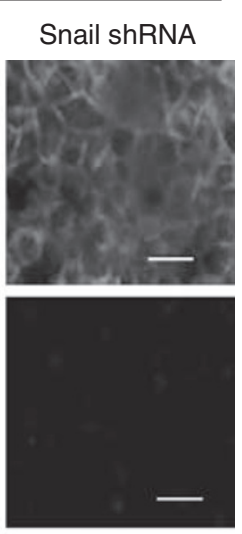

Snail

Figure 4 Molecular markers confirm that LMPI induces EMT through Snail in NP69SV40T nasopharyngeal cells. (A) Transfection of LMPI does not change levels of Twist in NP69SV40T cells. (B) Expression of representative epithelial markers, E-cadherin and $\alpha$-catenin, and mesenchymal markers, vimentin and N-cadherin, together with LMPI and Snail in NP69SV40T cell clones is shown by western blotting. (C) Immunofluorescence staining for a representative epithelial marker, E-cadherin, and mesenchymal marker, N-cadherin, in NP69SV40T cell clones together with staining for Snail are shown. Bars, $20 \mu \mathrm{m}$.

\section{DISCUSSION}

Epithelial-mesenchymal transition has recently been proposed as a major metastasis-promoting mechanism and implicated in several types of invasive human malignancies (Yang and Weinberg, 2008; Thiery et al, 2009). The genesis of EMT and its oncogenic role in carcinomas are beginning to be clarified. We reported earlier the novel finding that EMT is induced by LMPI, the EBV oncoprotein that is a member of the TNFR super-family, and contributes to metastatic features of NPC (Horikawa et al, 2007). Recent studies of EMT are generating a major shift in thinking in the field of cancer metastasis (Ansieau et al, 2008; Klein, 2008; Mani et al, 2008; Sánchez-García, 2009). Metastasis has generally been considered to result from the accumulation of genetic and epigenetic changes in the primary tumour as a final step in oncogenesis. This long-held view is increasingly challenged by a new early metastasis model operating through EMT, which postulates that metastasis occurs beginning at an early phase in tumour development (Ansieau et al, 2008; Klein, 2008; Mani et al, 2008; Sánchez-García, 2009). Nasopharyngeal carcinoma, a carcinoma characterized by its proclivity to invade and metastasise early, has several EMT-like features (Lo et al, 2004; Wei and Sham, 2005). Therefore, in this study, we have again focused on NPC as a biologically useful model for study of EMT and metastasis.

We report here that the EMT regulator, Snail, as well as Twist are overexpressed in NPC and that expression of LMP1 and Snail 
correlated with each other in NPC. Moreover, expression of Snail correlated independently inversely with expression of E-cadherin, and was associated with metastasis in NPC. By contrast, expression of Twist had no association with expression of E-cadherin. Further, in the human nasopharyngeal epithelial cell line, NP69SV40T, LMP1 could induce EMT, and Snail, but not Twist, played a pivotal role in this context. Nasopharyngeal carcinoma stands out for its highly metastatic character and undifferentiated histopathology among head-and-neck carcinomas (Lo et al, 2004; Wei and Sham, 2005). This study strengthens our view that the genesis of EMT by EBV LMP1 contributes to the distinctive early metastatic character of NPC. These findings also raise the possibility that NPC offers a clinical model for EMT. Intriguingly, and differing from our earlier finding in canine cells, this study newly suggests Snail as the pivotal EMT regulator in NPC.

Several EMT regulators show varied expression and roles in different kinds of cell lines and in different human carcinomas. Different patterns of expression of Snail, SIP1 and Twist according to histological subtype are reported for gastric cancer (Rosivatz et al, 2002). In breast cancer, Twist and Slug are upregulated and associated with progression, whereas Snail is downregulated (Martin et al, 2005). Slug expression is associated with downregulation of E-cadherin in diffuse and intestinal-type gastric carcinoma, and this effect is complemented by SIP1 and Snail (Castro Alves et al, 2007). Studies of prostate cancer have revealed that Snail and Slug lead to a reduction of E-cadherin expression, and Twist leads to a further decrease (Alexander et al, 2006). In our study, the levels of SIP1 and Slug were marginal and had no association with clinical parameters in NPC, whereas Snail and Twist were clearly overexpressed and showed significant positive correlation with metastasis. Moreover, Snail by itself, but not Twist, inversely correlated with E-cadherin, which suggests Snail's dominant role in the progression of EMT in NPC. Previously, we reported the key role of Twist in EMT in MDCK cells (Horikawa et al, 2007). Here, we have identified the central role of Snail in EMT in NP69SV40T human nasopharyngeal cells. The discrepancy may be attributed to differences in cell species and perhaps also cell type. MDCK cells are the first and most used model cell system for the study of EMT (Lo et al, 2004), but it is literally a cell line of canine-kidney origin. The immortalised human nasopharyngeal epithelial cell line, NP69SV40T, retains many characteristics of normal nasopharyngeal cells and is highly responsive to EBV LMP1 (Tsao et al, 2002). As LMPI is expressed in earliest stages of the genesis of NPC (Raab-Traub, 2002; Pagano et al, 2004; Pagano, 2009), we view these cells as offering the first credible cell-culture model for premalignant nasopharyngeal epithelial cells. The behaviour of Snail in these nasopharyngeal cells underscores the prime role of Snail in EMT in relation to NPC, but Twist may also have functions in this context. Its overexpression is reported to induce angiogenesis and chromosomal instability in vivo (Mironchik et al, 2005), and Twist inhibits both p53-dependent and p53-independent apoptosis and favors cell survival (Puisieux et al, 2006). The mechanisms of EMT and metastasis in NPC are undoubtedly diverse, but the current results clearly point to a pivotal role for Snail in EMT and metastasis of NPC. This study lends substantial credibility to the importance of EMT in metastasis of human carcinoma. Investigation of EMT in NPC is likely to continue to illuminate the mechanisms of metastasis of NPC and an array of human carcinomas.

\section{ACKNOWLEDGEMENTS}

We thank Drs Gerhard Christofori, Sai Wah Tsao, Erik K, Flemington and Hideaki Kato, respectively, for Snail shRNA, NP69SV40T cell line, Ad-AH cell line and NPC specimens. We thank Dr Robert Schoonhoven for help with immunohistochemistry, and Drs Edward Gershburg, Yojiro Kotake, Yuichi Tsukada and Yuki Okada for helpful advice. This work was supported by NCI (CA 19014) (JSP) and a Japan Herpesvirus Infections Forum scholarship (TH).

\section{REFERENCES}

Alexander NR, Tran NL, Rekapally H, Summers CE, Glackin C, Heimark RL (2006) $\mathrm{N}$-cadherin gene expression in prostate carcinoma is modulated by integrin-dependent. Cancer Res 66: 3365-3369

Ansieau S, Bastid J, Doreau A, Morel AP, Bouchet BP, Thomas C, Fauvet F, Puisieux I, Doglioni C, Piccinin S, Maestro R, Voeltzel T, Selmi A, Valsesia-Wittmann S, Caron de Fromentel C, Puisieux A (2008) Induction of EMT by twist proteins as a collateral effect of tumorpromoting inactivation of premature senescence. Cancer Cell 14: 79-89

Bachelder RE, Yoon SO, Franci C, de Herreros AG, Mercurio AM (2005) Glycogen synthase kinase-3 is an endogenous inhibitor of Snail transcription: implications for the epithelial-mesenchymal transition. J Cell Biol 168: 29-33

Barberà MJ, Puig I, Domínguez D, Julien-Grille S, Guaita-Esteruelas S, Peiró S, Baulida J, Francí C, Dedhar S, Larue L, García de Herreros A (2004) Regulation of snail transcription during epithelial to mesenchymal transition of tumor cells. Oncogene 23: 7345-7354

Blanco MJ, Moreno-Bueno G, Sarrio D, Locascio A, Cano A, Palacios J, Nieto MA (2002) Correlation of snail expression with histological grade and lymph node status in breast carcinomas. Oncogene 21: $3241-3246$

Cano A, Pérez-Moreno MA, Rodrigo I, Locascio A, Blanco MJ, del Barrio MG, Portillo F, Nieto MA (2000) The transcription factor snail controls epithelial-mesenchymal transitions by repressing E-cadherin expression. Nat Cell Biol 2: 76-83

Castro Alves C, Rosivatz E, Schott C, Hollweck R, Becker I, Sarbia M, Carneiro F, Becker KF (2007) Slug is overexpressed in gastric carcinomas and may act synergistically with SIP1 and snail in the down-regulation of E-cadherin. J Pathol 211: 507-515

Elloul S, Elstrand MB, Nesland JM, Tropé CG, Kvalheim G, Goldberg I, Reich R, Davidson B (2005) Snail, slug, and smad-interacting protein 1 as novel parameters of disease aggressiveness in metastatic ovarian and breast carcinoma. Cancer 103: $1631-1643$

Endo K, Kondo S, Shackleford S, Horikawa T, Kitagawa N, Yoshizaki T, Furukawa M, Zen Y, Pagano JS (2009) Phosphorylated ezrin is associated with EBV latent membrane protein 1 in nasopharyngeal carcinoma and induces cell migration. Oncogene 28: 1725-1735

Gershburg E, Marschall M, Hong K, Pagano JS (2004) Expression and localization of the Epstein-Barr virus-encoded protein kinase. J Virol 78: $12140-12146$

Grotegut S, von Schweinitz D, Christofori G, Lehembre F (2006) Hepatocyte growth factor induces cell scattering through MAPK/Egr-1-mediated upregulation of Snail. EMBO J 25: $3534-3545$

Horikawa T, Sheen TS, Takeshita H, Sato H, Furukawa M, Yoshizaki T (2001) Induction of c-Met proto-oncogene by Epstein-Barr virus latent membrane protein-1 and the correlation with cervical lymph node metastasis of nasopharyngeal carcinoma. Am J Pathol 159: $27-33$

Horikawa T, Yang J, Kondo S, Yoshizaki T, Joab I, Furukawa M, Pagano JS (2007) Twist and epithelial-mesenchymal transition are induced by the Epstein-Barr Virus oncoprotein latent membrane protein 1 and are associated with metastatic nasopharyngeal carcinoma. Cancer Res 67: $1970-1978$

Horikawa T, Yoshizaki T, Sheen TS, Lee SY, Furukawa M (2000) Association of latent membrane protein 1 and matrix metalloproteinase 9 with metastasis in nasopharyngeal carcinoma. Cancer 89: 715-723

Kaye KM, Izumi MK, Mosialos G, Kieff E (1995) The Epstein-Barr virus LMP1 cytoplasmic carboxy terminus is essential for B-lymphocyte transformation: fibroblast cocultivation complements a critical function within the terminal 155 residues. J Virol 69: 675-683

Klein CA (2008) Cancer. The metastasis cascade. Science 321(5897): $1785-1787$ 
Knecht H, Berger C, Rothenberger S, Odermatt BF, Brousset P (2001) The role of Epstein-Barr virus in neoplastic transformation. Oncology 60: 289-302. Review

Kondo S, Seo SY, Yoshizaki T, Wakisaka N, Furukawa M, Joab I, Jang KL, Pagano JS (2006a) EBV latent membrane protein 1 up-regulates hypoxiainducible. Cancer Res 66: 9870 - 9877

Kondo S, Seo SY, Yoshizaki T, Wakisaka N, Furukawa M, Joab I, Jang KL, Pagano JS (2006b) Epstein-Barr Virus latent membrane protein 1 upregulates HIF1 $\alpha$ through Siah1-mediated down-regulation of prolyl hydroxylases 1 and 3 in nasopharyngeal epithelial cells. Cancer Res 66: $9870-9877$

Kondo S, Wakisaka N, Schell MJ, Horikawa T, Sheen TS, Sato H, Furukawa M, Pagano JS, Yoshizaki T (2005) Epstein-Barr virus latent membrane protein 1 induces the matrix metalloproteinase-1 promoter via an Ets binding site formed by a single nucleotide polymorphism: enhanced susceptibility to nasopharyngeal carcinoma. Int J Cancer 115: $368-376$

Kondo S, Yoshizaki T, Wakisaka N, Murono S, Jang KL, Joab I, Furukawa M, Pagano JS (2007) MUC1 induced by Epstein-Barr Virus latent membrane protein 1 causes dissociation of cell-matrix interaction and cellular invasiveness via STAT signaling. J Virol 81: 1554-1562

Lo AK, Lo KW, Tsao SW, Wong HL, Hui JW, To KF, Hayward DS, Chui YL, Lau YL, Takada K, Huang DP (2006) Epstein-Barr virus infection alters cellular signal cascades in human nasopharyngeal epithelial cells. Neoplasia 8: $173-180$

Lo KW, To KF, Huang DP (2004) Focus on nasopharyngeal carcinoma. Cancer Cell 5: 423-428. Review

Mani SA, Guo W, Liao MJ, Eaton EN, Ayyanan A, Zhou AY, Brooks M, Reinhard F, Zhang CC, Shipitsin M, Campbell LL, Polyak K, Brisken C, Yang J, Weinberg RA (2008) The epithelial-mesenchymal transition generates cells with properties of stem cells. Cell 133: 704-715

Marks JE, Phillips JL, Menck HR (1998) The National Cancer Data Base report on the relationship of race and national origin to the histology of nasopharyngeal carcinoma. Cancer 83: $582-588$

Martin TA, Goyal A, Watkins G, Jiang WG (2005) Expression of the transcription factors snail, slug, and twist and their clinical significance in human breast cancer. Ann Surg Oncol 12: 488-496

Mironchik Y, Winnard Jr PT, Vesuna F, Kato Y, Wildes F, Pathak AP, Kominsky S, Artemov D, Bhujwalla Z, Van Diest P, Burger H, Glackin C, Raman V (2005) Twist overexpression induces in vivo angiogenesis and correlates with chromosomal instability in breast cancer. Cancer Res 65: $10801-10809$

Moody SE, Perez D, Pan TC, Sarkisian CJ, Portocarrero CP, Sterner CJ, Notorfrancesco KL, Cardiff RD, Chodosh LA (2005) The transcriptional repressor Snail promotes mammary tumor recurrence. Cancer Cell 8: $197-209$

Murono S, Inoue H, Tanabe T, Joab I, Yoshizaki T, Furukawa M, Pagano JS (2001) Induction of cyclooxygenase-2 by Epstein-Barr virus latent membrane protein 1 is involved in vascular endothelial growth factor production in nasopharyngeal carcinoma cells. Proc Natl Acad Sci USA 98: $6905-6910$

Murono S, Yoshizaki T, Sato H, Takesita H, Furukawa M, Pagano JS (2000) Aspirin inhibits tumor cell invasiveness induced by Epstein-Barr virus latent membrane protein 1 through suppression of matrix metalloproteinase-9 expression. Cancer Res 60: 2555-2561

Pagano JS (2009) EBV Diseases, Chapter 10, In DNA Tumor Viruses, Damania B, Pipas JM (eds), pp 217-240. Springer: Berlin

Pagano JS (2010) Molecular pathobiology of EBV infection. In Viral Oncology: Basic Science and Clinical Applications, Khalili K, Jeang $\mathrm{K}$ (eds), pp 409-451. John Wiley \& Sons: New York

Pagano JS, Blaser M, Buendia MA, Damania B, Khalili K, Raab-Traub N, Roizman B (2004) Infectious agents and cancer: criteria for a causal relation. Semin Cancer Biol 14: 453-471
Pathmanathan RU, Prasad U, Sadler R, Flynn K, Raab-Traub N (1995) Clonal proliferations of cells infected with Epstein-Barr virus in preinvasive lesions related to nasopharyngeal carcinoma. $N$ Engl J Med 333: $693-698$

Puisieux A, Valsesia-Wittmann S, Ansieau S (2006) A twist for survival and cancer progression. Br J Cancer 94: 13-17. Review

Raab-Traub N (2002) Epstein-Barr virus in the pathogenesis of NPC. Semin Cancer Biol 12: 431 - 441

Rees JR, Onwuegbusi BA, Save VE, Alderson D, Fitzgerald RC (2006) In vivo and. Cancer Res 66: $9583-9590$

Rosivatz E, Becker I, Specht K, Fricke E, Luber B, Busch R, Höfler H, Becker KF (2002) Differential expression of the epithelial-mesenchymal transition regulators snail, SIP1, and twist in gastric cancer. Am J Pathol 161: $1881-1891$

Sánchez-García I (2009) The crossroads of oncogenesis and metastasis. $N$ Engl J Med 360: 297 - 299

Sarac S, Akyol MU, Kanbur B, Poyraz A, Akyol G, Yilmaz T, Sungur A (2001) Bcl-2 and LMP1 expression in nasopharyngeal carcinomas. Am J Otolaryngol 22: 377 - 382

Takeshita H, Yoshizaki T, Miller WE, Raab-Traub N, Pagano JS (1999) The Epstein-Barr virus latent membrane protein 1 C-terminal activation regions 1 and 2. J Virol 173: 5548-5555

Thiery JP, Acloque H, Huang RY, Nieto MA (2009) Epithelialmesenchymal transitions in development and disease. Cell 139: $871-890$. Review

Tsao SW, Wang X, Liu Y, Cheung YC, Feng H, Zheng Z, Wong N, Yuen PW, Lo AK, Wong YC, Huang DP (2002) Establishment of two immortalized nasopharyngeal epithelial cell lines using SV40 large T and HPV16E6/E7 viral oncogenes. Biochim Biophys Acta 1590: $150-158$

Wakisaka N, Kondo S, Yoshizaki T, Murono S, Pagano JS (2004) EpsteinBarr virus latent membrane protein 1 induces synthesis of hypoxiainducible factor 1 alpha. Mol Cell Biol 24: 5223-5234

Wakisaka N, Pagano JS (2003) Epstein-Barr virus induces invasion and metastasis factors. Anticancer Res 23: $2133-2138$

Wakisaka N, Murono S, Yoshizaki T, Furukawa M, Pagano JS (2002) Epstein-Barr virus latent membrane protein 1 induces and causes release of fibroblast growth factor-2. Cancer Res 62: 6337-6344

Wei WI, Sham JS (2005) Nasopharyngeal carcinoma. Lancet 365: 2041 - 2054. Review

Yang J, Mani SA, Donaher JL, Ramaswamy S, Itzykson RA, Come C, Savagner P, Gitelman I, Richardson A, Weinberg RA (2004) Twist, a master regulator of morphogenesis, plays an essential role in tumor metastasis. Cell 117: $927-939$

Yang J, Weinberg RA (2008) Epithelial-mesenchymal transition: at the crossroads of development and tumor metastasis. Dev Cell 14: $818-829$

Yang MH, Chen CL, Chau GY, Chiou SH, Su CW, Chou TY, Peng WL, Wu JC (2009) Comprehensive analysis of the independent effect of twist and snail in promoting metastasis of hepatocellular carcinoma. Hepatology 50: $1464-1474$

Yoshizaki T, Horikawa T, Qing-Chun R, Wakisaka N, Takeshita H, Sheen TS, Lee SY, Sato H, Furukawa M (2001) Induction of interleukin-8 by Epstein-Barr virus latent membrane protein-1 and its correlation to angiogenesis in nasopharyngeal carcinoma. Clin Cancer Res 7: $1946-1951$

Yoshizaki T, Sato H, Furukawa M, Pagano JS (1998) The expression of matrix metalloproteinase 9 is enhanced by Epstein-Barr virus latent membrane protein 1. Proc Natl Acad Sci USA 95: 3261 - 3266

Yoshizaki T, Wakisaka N, Pagano JS (2005) Epstein-Barr virus, invasion and metastasis, Chapter 12. In Epstein-Barr Virus, Robertson ES (ed), pp $171-196$. Caister Academic Press: Norfolk 